\title{
METODE AGILE DALAM PERANCANGAN SISTEM PREDIKSI PREVALENSI STUNTING DI INDONESIA
}

\author{
Danang Arbian Sulistyo ${ }^{1)}$, Yogie Susdyastama Putra ${ }^{2)}$, Suastika Yulia Riska ${ }^{2)}$ \\ 1),2),3) Program Studi Teknik Informatika, Fakultas Teknologi dan Desain, Institut Teknologi dan \\ Bisnis Asia Malang \\ Jl. Soekarno - Hatta Rembuksari no. 1A, Malang

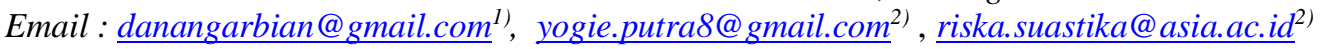

\begin{abstract}
Abstrak
Stunting merupakan kejadian balita pendek dan berhubungan dengan gizi. Anak yang menderita stunting akan lebih rentan terhadap penyakit, dan dalam jangka panjang akan mempengaruhi kecerdasan pada anak.Untuk meminimalisir kasus stunting perlu dirancang sistem prediksi berbasis web sehingga dapat diakses oleh dinas kesehatan seluruh Indonesia. Sebelum mengembangkan suatu sistem perlu dilakukan perancangan sistem yang dapat mempermudah proses pengembangan sistemnya. Pada penelitian ini menerapkan Metode Agile untuk perancangan sistem. Adapun tahapan metode ini mencakup define, build, dan release. Dari ketiga tahap tersebut dapat dilakukan iterasi berulang kali berdasarkan identifikasi sistem. Dengan menggunakan metode Agile, sistem ini lebih sederhana dan dapat dikembangkan sesuai dengan kebutuhan. Hasil perancangan menunjukkan bahwa sistem akan dapat mengolah data untuk prediksi dan akan menampilkan data sebaran setiap provinsi.
\end{abstract}

Kata kunci: Perancangan Web, Metode Agile, Prevalensi Stunting

\begin{abstract}
Stunting is a short toddler event and is related to nutrition. Children who suffer from stunting will be more susceptible to disease, and in the long run will affect intelligence on children. To minimize stunting cases, a web-based prediction sistem should be made so that it can be accessed by health services throughout Indonesia. Before developing a sistem, it is necessary to design a sistem that can simplify the process of developing the sistem. In this study applying the Agile Method for sistem design. The stages of this method include define, build, and release. Of the three stages iterations can be repeated repeatedly based on sistem identification. By using the Agile method, this system is simpler and can be developed according to needs. The design results show that the system will be able to process data for predictions and will display the distribution data for each province.
\end{abstract}

Keywords :Web Design, Agile Method, Prevalensi Stunting

\section{PENDAHULUAN}

Stunting adalah salah satu masalah kesehatan yang perlu dijadikan perhatian khusus oleh pemerintah. Stunting adalah masalah gizi kronis pada balita yang ditandai dengan tinggi badan yang lebih pendek dibandingkan dengan anak seusianya. Jika anak sudah menderita stunting maka anak tersebut akan lebih rentan terhadap penyakit dan memiliki risiko yang lebih tinggi untuk mengidap penyakit degenerative ketika dewasa. Selain dampak dari segi kesehatan, stunting juga akan mempengaruhi tingkat kecerdasan anak[1]. Maka pemerintah perlu memikirkan solusi dari segala sektor, tidak hanya dari sector kesehatan akan tetapi dari sector ketersediaan pangan dengan harga yang terjangkau, sector pendidikan yaitu dengan memberikan pemahaman yang cukup kepada masyarakat tentang pentingnya memperhatikan gizi, maupun dari sector teknologi, misalkan dengan membuat sistem yang dapat memprediksi zona stunting. Guna membantu pemerintah dalam menangani permasalahan tersebut, maka tujuan dari penelitian ini adalah untuk mengembangkan sebuah sistem tipe zona stunting dengan output yaitu zona hijau/tipe D, zona kuning/tipeC, zona merah/tipe B dan zona hitam/tipe A.

Penelitian tentang pembuatan sistem yang dapat membantu menangani permasalahan stunting sudah pernah dilakukan oleh beberapa peneliti sebelumnya. Diantaranya penelitian yang dilakukan oleh Syafi'ie dkk[2], yaitu tentang Sistem Pendukung Keputusan pemilihan daerah 
prioritas penanganan stunting pada balita menggunakan metode TOPSIS di Pontianak. Hasil dari penelitian tersebut adalah sistem layak diimplementasikan karena hasil kuisioner dengan tiga aspek penilaian yaitu aspek rekayasa perangkat lunak, aspek fungsionalitas perangkat lunak, dan aspek visual perangkat lunak memiliki rata-rata $80 \%$. Oleh karena itu peneliti tertarik untuk melanjutkan penelitian tersebut, yaitu dengan mengembangkan sebuah sistem prediksi zona stunting pada seluruh wilayah di Indonesia, tidak hanya pada wilayah tertentu.

Adapun metode yang digunakan dalam proses perancangan sistem prediksi stunting ini adalah metode Agile. Metode Agile merupakan metode pengembangan incremental yang fokus pada perkembangan yang cepat, perangkat lunak yang dirilis bertahap, mengurangi overhead proses, dan menghasilkan kode berkualitas tinggi dan pada proses perkembangannya melibatkan pelanggan secara langsung[3]. Selain itu perancangan sistem ini digunakan alat bantu pengembangan sistem yaitu Flowchart, Context Diagram, Data Flow Diagram (DFD), dan Entity Relationship Diagram (ERD) [4].

Dibutuhkan Pendokumentasian sistem untuk membuat atau mengontrol bagian mana yang dapat dilakukan pengembangan. Dengan hasil analisa, sistem lama yang dihasilkan bisa dijadikan acuan untuk penelitian selanjutnya untuk melakukan desain sistem kembali untuk perbaikan [5]. Pendokumentasian rancangan sebuah sistem dirasa perlu agar didapat sistem yang terstruktur dan sesuai dengan yang diharapkan.

\section{DASAR TEORI}

Stunting adalah salah satu keadaan malnutrisi yang berhubungan dengan ketidakcukupan zat gizi masa lalu sehingga termasuk dalam masalah gizi yang bersifat kronis. Prevalensi stunting di Indonesia lebih tinggi daripada negaranegara lain di Asia Tenggara, seperti Myanmar (35\%), Vietnam (23\%), dan Thailand (16\%) dan menduduki peringkat kelima dunia. Stunting disebabkan oleh faktor multi dimensi dan tidak hanya disebabkan oleh faktor gizi buruk yang dialami oleh ibu hamil maupun anak balita[4].

Pada tahun 2013 prevalensi stunting dan severe stunting adalah 26,9\% dan 16,8\%. Prevalensi tersebut lebih tinggi dibandingkan prevalensi di Jawa Tengah yang hanya sebesar $11,0 \%$. Penelitian ini bertujuan untuk mengetahui faktor risiko kejadian stunting pada anak umur 12 -24 bulan di Kecamatan Brebes [5].

Stunting merupakan permasalahan gizi kronis yang terjadi karena asupan zat gizi yang kurang dalam jangka waktu yang lama, sehingga menyebabkan gangguan pertumbuhan yang ditandai dengan tinggi badan yang tidak sesuai dengan umur. Kejadian stunting pada balita dipengaruhi oleh rendahnya kemampuan akses terhadap makanan baik dari segi kuantitas maupun kualitas. Selain itu juga dipengaruhi oleh pola asuh makan yang diterapkan oleh ibu terutama pada praktek pemberian makan pada balita[6].

Scalling Up Nutrition (SUN) merupakan upaya global dalam rangka rencana aksi percepatan perbaikan gizi salah satunya menanggulangi balita stunting fokus pada 1000 Hari Pertama Kehidupan (HPK). Stunting merupakan prevalensi tertinggi di Wilayah kerja Puskesmas Sir-ampog di Kabupaten Brebes, ini menunjukkan bahwa kualitas pelayanan kesehatan masih rendah. Tujuan penelitian ini adalah untuk mengevaluasi penatalaksanaan status gizi balita stunting dengan unsur input, proses dan output[7].

Metode Agile dapat diterapkan dalam pengembangan sebuah perangkat lunak, metode ini merupakan jenis pengembangan jangka pendek, sesuai dengan tujuan penelitian sistem prediksi stunting, metode ini beradaptasi dengan cepat terhadap perubahan. Dalam metode Agile interaksi dan personel lebih penting ketimbang proses dan alat, perangkat lunak yang berfungsi lebih penting daripada dokumentasi, kolaborasi dengan client lebih penting daripada kontrak dan sikap terhadap perubahan lebih penting daripada mengikuti rencana[8]. 


\section{METODOLOGI PENELITIAN}

Berdasarkan hasil analisis kebutuhan yang digunakan dalam perancangan Sistem Prediksi Zona Prevalensi Stunting di Indonesia, penelitian ini menerapkan metode Agile. Data yang nantinya diolah merupakan data dari kementrian kesehatan dan tim nasional percepatan penanggulangan kemiskinan. Adapun contoh data yang nantinya digunakan dalam proses prediksi ditunjukkan pada Tabel 1.

Tabel 1. Data Prevalensi Zona Stunting Berdasarkan Provinsi

\begin{tabular}{|c|c|c|c|c|c|c|c|c|c|}
\hline \multirow{2}{*}{ No } & \multirow{2}{*}{ Provinsi } & \multicolumn{4}{|c|}{ Penanganan untuk Faktor Ibu } & \multicolumn{4}{|c|}{ Penanganan untuk Faktor Bayi (\%) } \\
\hline & & A & $\mathrm{B}$ & $\mathrm{C}$ & $\mathrm{D}$ & $\mathrm{E}$ & $\mathrm{F}$ & $\mathrm{G}$ & $\mathrm{H}$ \\
\hline 1 & Aceh & 78.8 & 99.5 & 79.01 & 36.07 & 81.17 & 97.3 & 54.2 & 86.7 \\
\hline 2 & Bali & 92.08 & 97.81 & 91.81 & 100 & 99.65 & 46.7 & 61.61 & 88.2 \\
\hline 3 & Sumatra Utara & 78.02 & 86.59 & 87.09 & 46.06 & 81.25 & 57.47 & 45.74 & 87.8 \\
\hline 4 & Sulawesi Utara & 49.42 & 54.59 & 63.17 & 64.02 & 74.17 & 43.78 & 36.93 & 84.6 \\
\hline 5 & Gorontalo & 90.65 & 97.64 & 82.34 & 10.75 & 98.68 & 87.76 & 47.69 & 97.1 \\
\hline 6 & $\begin{array}{l}\text { Kalimantan } \\
\text { Utara }\end{array}$ & 79.14 & 76.08 & 95.75 & 55.1 & 75.39 & 58.61 & 52.93 & 75.1 \\
\hline 7 & Maluku Utara & 49.93 & 75.68 & 55.44 & 3.1 & 42.87 & 75.88 & 63.6 & 64 \\
\hline
\end{tabular}

Berdasarkan Tabel 1, Penanganan Faktor Ibu dan Bayi meliputi: (A) Pil Tambah Darah Ibu Hamil (B) Ibu Hamil KEK Mendapat Makanan Tambahan (C) Cakupan Pelayanan Kesehatan Ibu Hamil K4 (D) Puskesmas Melaksanakan Kegiatan Kesehatan Remaja (E) Balita Kurus Mendapat Tambahan (PMT) (F) IMD (G) Asi Eksklusif (H) Keberhasilan Penanganan TB.

Secara umum, terdapat 3 tahap yang dilalui, yaitu define, build, dan release. Pada perancangan sistem ini, dilakukan identifikasi masalah, dengan melihat kebutuhan fungsional yang dibutuhkan oleh user, kemudian melakukan pengembangan sistem secara berkala. Setelah itu melakukan evaluasi kebutuhan fungsional kembali. Jika terdapat hal-hal yang belum diidentifikasi sebelumnya, maka diproses kembali dalam pengembangan sistem. Hal tersebut berulang terus-menerus sampai sistem baik untuk digunakan. Secara umum, perancangan sistem prediksi digambarkan pada Gambar 1.

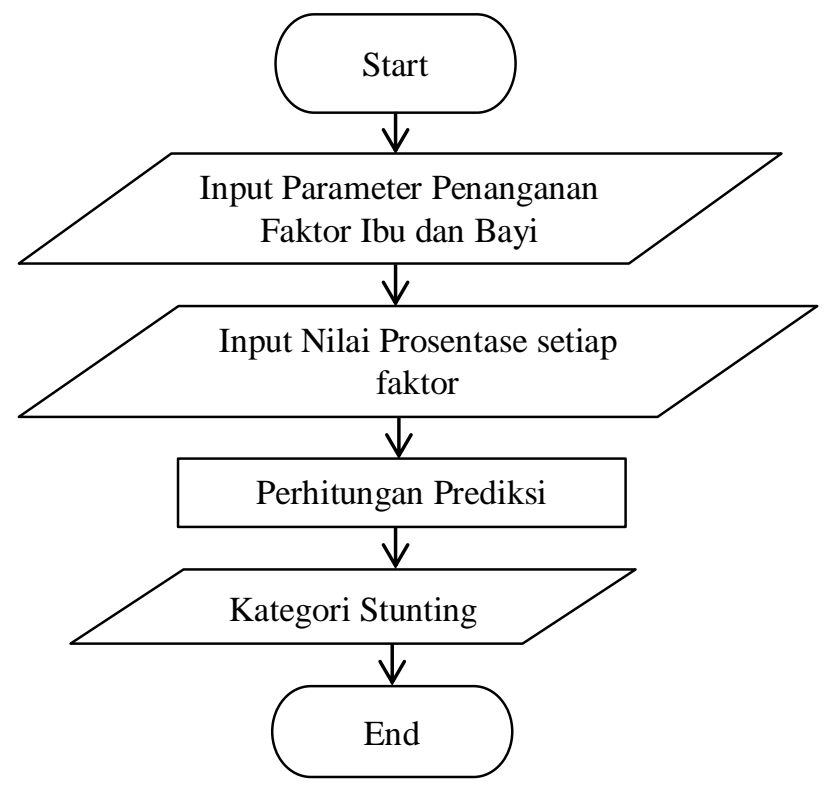

Gambar 1 Alur Perancangan Sistem Prediksi Zona Prevalensi Stunting 
Perancangan sistem menggunakan Metode Agile memiliki bebapa keuntungan dimana sangat tepat diterapkan untuk sistem yang sederhana, dan kebutuhan sistem yang berubah dengan cepat. Sistem ini nantinya dapat digunakan oleh kementrian kesehatan dan juga dinas kesehatan sebagai rekomendasi dalam memprediksi sebaran zona prevalensi Stunting di Indonesia. Sehingga, permasalahan stunting dapat segera teratasi dengan sistem prediksi ini. Secara detail proses Metode Agile dalam perancangan sistem prediksi zona prevalensi stunting di Indonesia ditunjukkan pada Gambar 2.

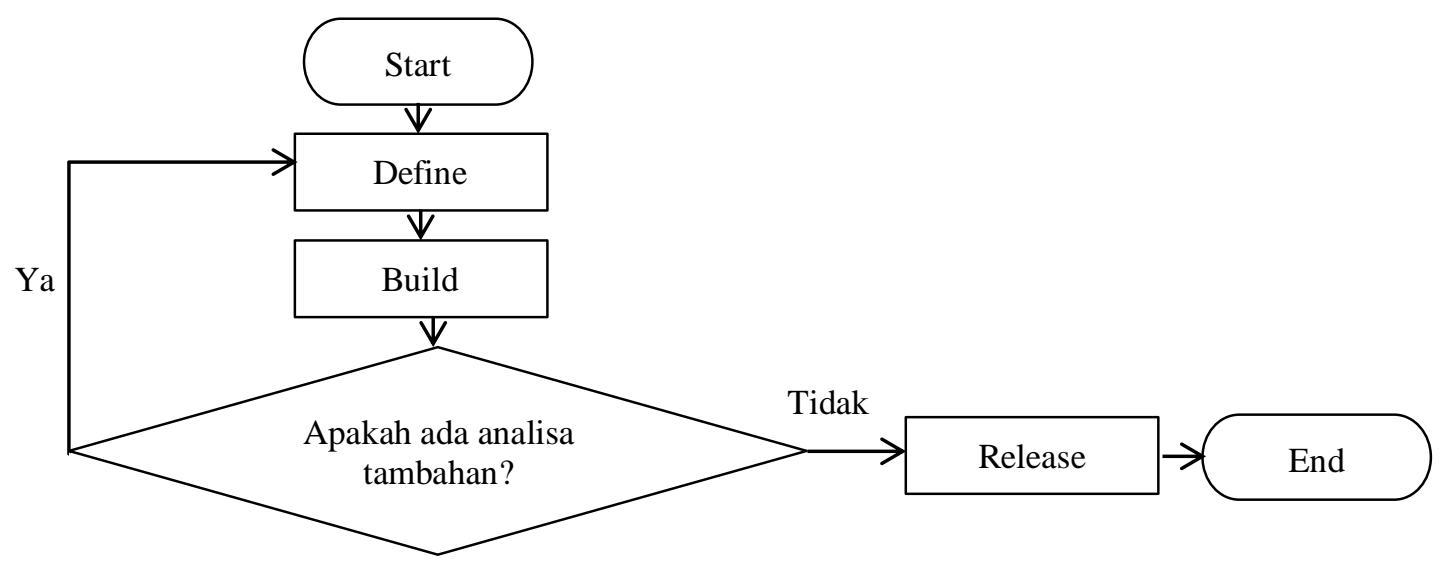

Gambar 2. Alur Metode Agile Dalam Perancangan Sistem

Berdasarkan Gambar 2, penerapan Metode Agile dalam proses Perancangan Sistem ini meliputi :

\section{A. Identifikasi (Define)}

Pada tahap ini dilakukan identifikasi kebutuhan fungsional sistem. Pada sistem ini akan dibagi menjadi 2 hak akses user, yaitu admin dan pimpinan yang ditunjukkan pada Gambar 3.

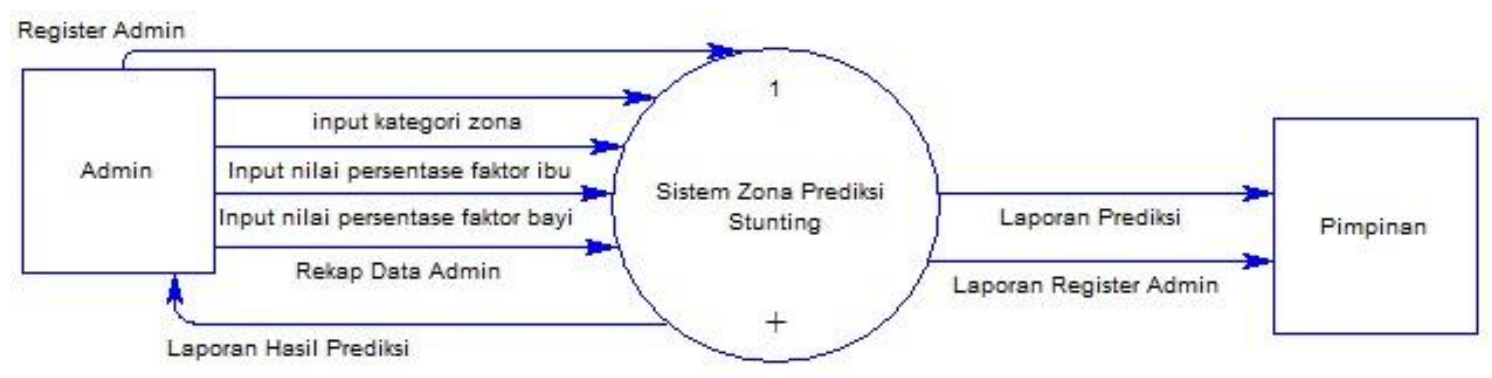

Gambar 3. DFD Level 0 Sistem

Berdasarkan Gambar 3, Admin dapat melakukan register agar bisa melakukan prediksi. Selain itu, admin dapat memanipulasi data dalam penentuan rule untuk melakukan prediksi. Untuk mendapatkan sebaran prediksi kasus stunting, maka admin dapat melakukan input nilai persentase factor ibu dan bayi. Sedangkan hak akses pimpinan adalah melihat laporan hasil persebaran prediksi sona stunting dari admin dan dapat melihat status admin. Adapun detail alur sistem digambarkan dalam DFD Level 1 yang ditunjukkan pada Gambar 4. 


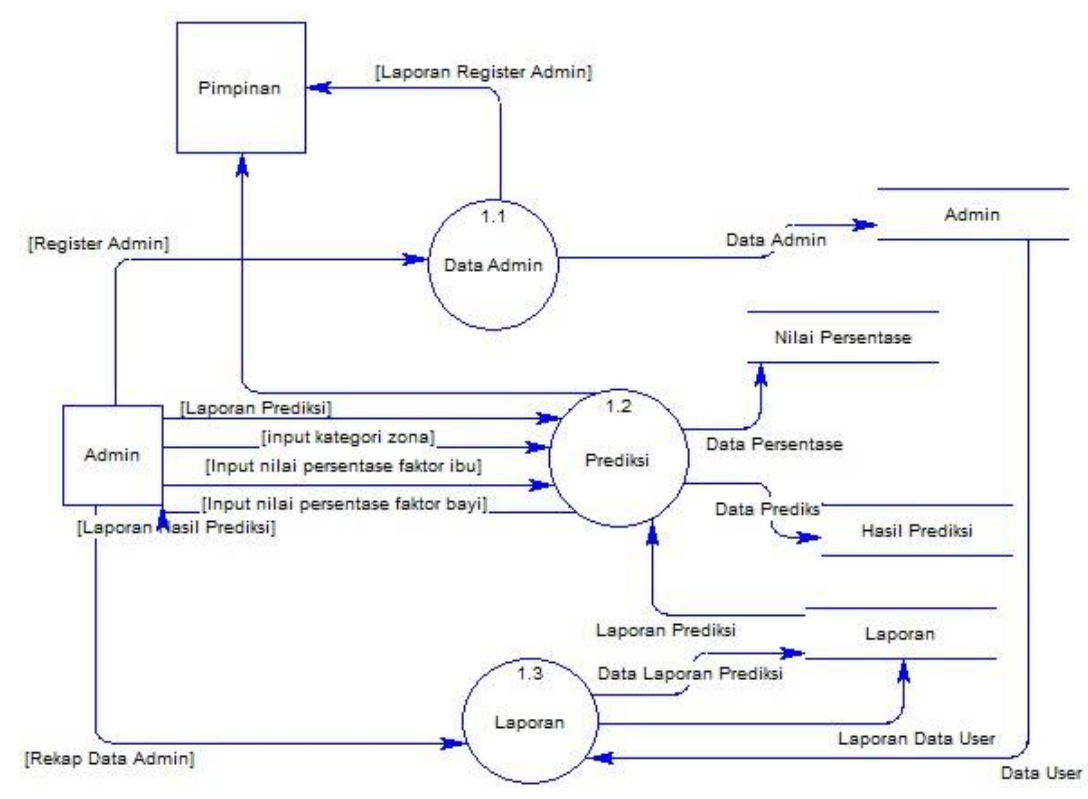

Gambar 4. DFD Level 1 Sistem

B. Pembuatan Perancangan Awal (Build)

Tahap build pada perancangan sistem ini adalah proses perancangan awal sistem dari hasil identifikasi kebutuhan fungsional sistem. Jika pada tahap ini terdapat analisa tambahan, maka dilakukan iterasi ke tahap define. Perancangan Login Form ditunjukkan pada Gambar 5.

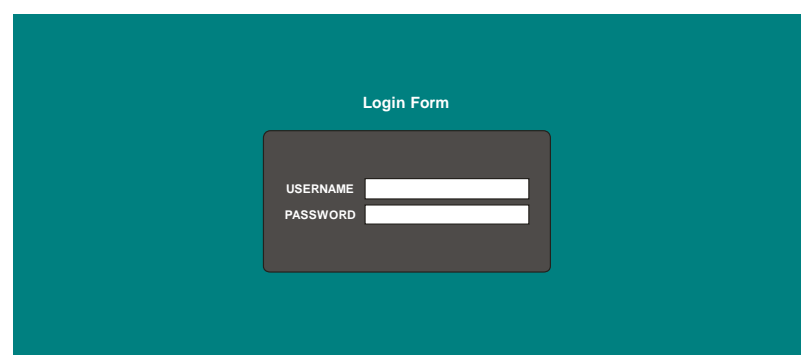

Gambar 5. Perancangan Login Form

Berdasarkan Gambar 4, Form ini digunakan oleh admin untuk memproses prediksi zona prevalensi stunting. Terdapat username dan password. Kemudian jika admin belum memiliki akun dapat sign up terlebih dahulu. Selanjutnya terdapat perancangan menu home yang ditunjukkan pada Gambar 5. Pada halaman ini akan diberikan penjelasan tentang stunting. Selain itu juga penjelasan tentang penanganan factor ibu dan bayi.

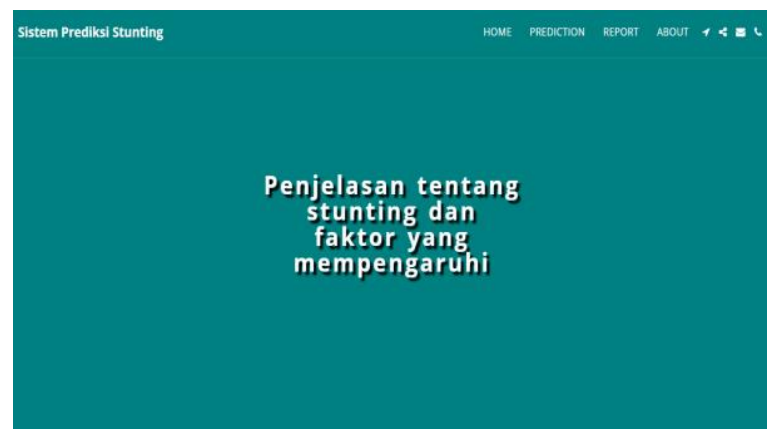

Gambar 6. Perancangan Menu Home

Selain menu home, juga terdapat perancangan menu prediction yang ditunjukkan pada Gambar 6 dan 7. 


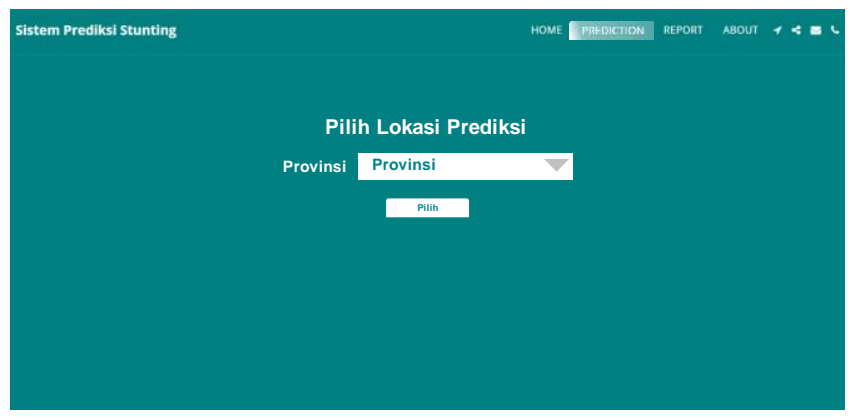

Gambar 7. Perancangan Menu Prediction

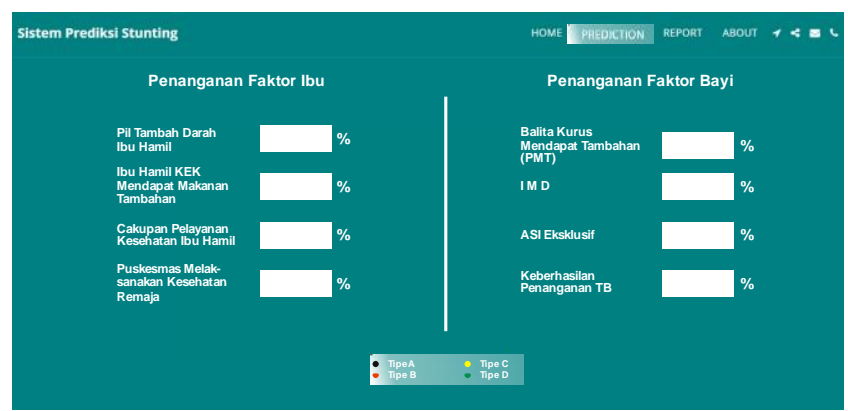

Gambar 8. Perancangan Menu Prediction

Pada halaman ini, user dapat memilih provinsi mana yang akan dilakukan prediksi. Menggunakan select box, agar memudahkan dalam pemilihan provinsi. Sehingga setelah memilih, pada halaman ini hanya akan menampilkan 1 provinsi yang dipilih. Setelah memilih provinsi, di dalam menu prediction akan menampilkan form yang akan diisi oleh admin. Nilai berupa prosentase setiap penanganan factor ibu dan bayi. Sehingga pada tahap ini akan ditampilkan provinsi yang dipilih sebelumnya, masuk dalam kategori zona A, B, C, atau D. Kemudian terdapat menu Report yang ditunjukkan pada Gambar 7.

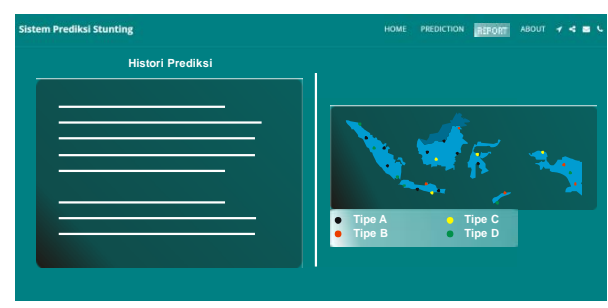

Gambar 9. Perancangan Menu Report

Pada menu ini terdapat history prediksi yang telah dilakukan oleh admin. Kemudian akan ditampilkan peta sebarannya sesuai kriteria Zona yang muncul pada Menu Prediction.

\section{Distribusi Perancangan (Release)}

Pada tahap ini dilakukan perancangan sistem berbasis website. Sistem ini nantinya akan dikembangkan secara online. Sehingga, dapat diakses juga oleh karyawan di dinas kesehatan provinsi. Pada saat dilakukan perancangan sistem menggunakan website, juga dilakukan analisa kebutuhan fungsional kembali. Sehingga sistem dapat digunakan secara maksimal.

\section{HASIL DAN PEMBAHASAN}

Hasil perancangan sistem dituangkan dalam sistem berbasis website. Beberapa gambar dalam sistem ini diambil dari google, untuk memvisualisasikan kondisi stunting. Hasil perancangan sistem ditunjukkan pada Gambar 8, login form dan sign up form yang ditunjukkan pada Gambar 9 dan 10. 

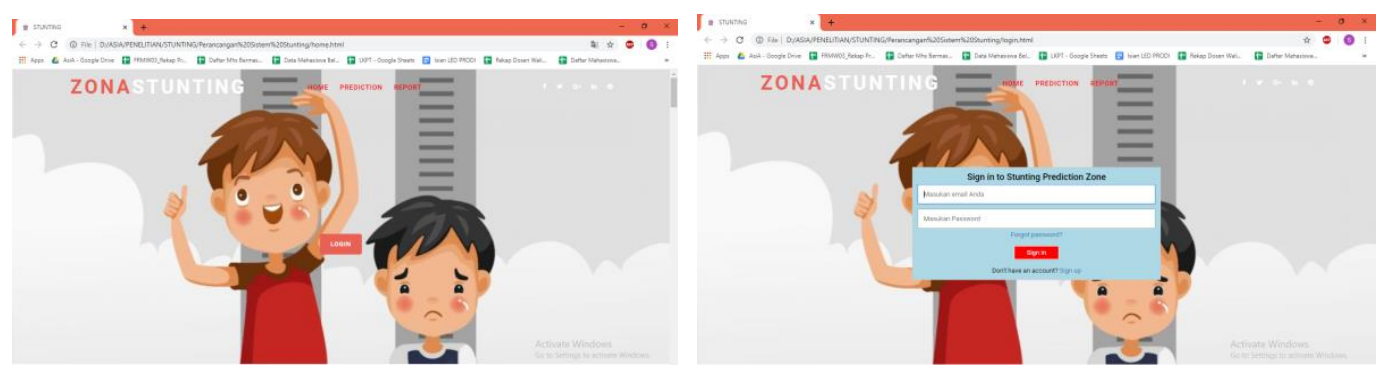

Gambar 10. (1) Hasil Perancangan Halaman Awal, (2) Hasil Perancangan Login Form.

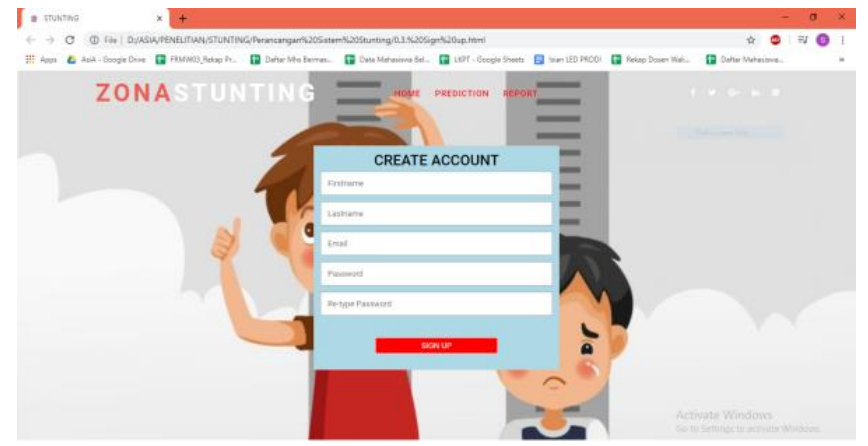

Gambar 11. Hasil Perancangan Sign Up Form

Gambar 10 merupakan halaman awal sebelum admin dapat melakukan login untuk memproses prediksi. User selain admin dapat langsung mengakses Home dan Report. Gambar 10 digunakan untuk admin memasukkan username dan password yang telah didaftarkan sebelumnya. Jika admin belum memiliki akun, maka dapat meng-klik sign-up terlebih dahulu, yang ditunjukkan pada Gambar 11. Pada Form ini digunakan untuk admin melakukan pendaftaran akun. Setelah akun terdaftar admin dapat melakukan login, kemudian melakukan prediksi untuk zona stunting. Menu home dari hasil perancangan system ini ditunjukkan pada Gambar 12.

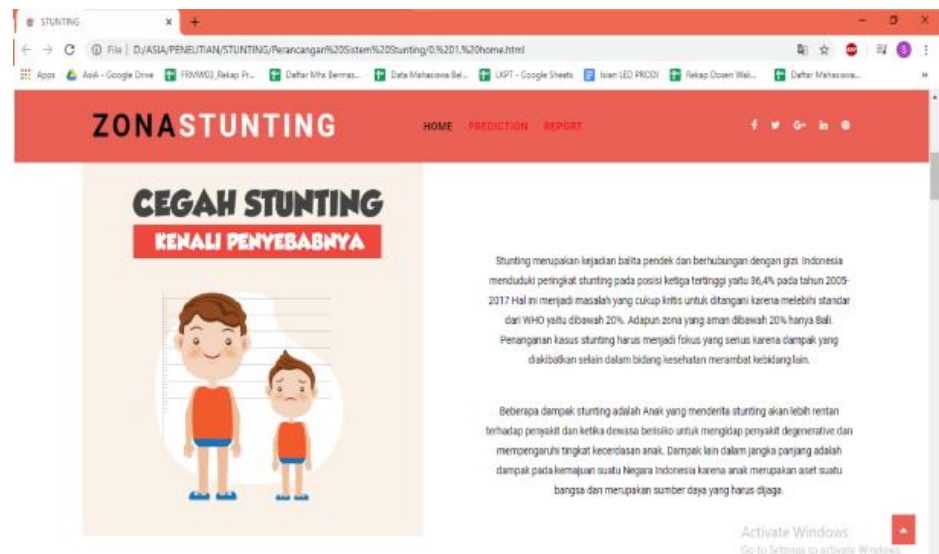

Gambar 12. Hasil Perancangan Home

Pada menu ini terdapat penjelasan tentang Stunting, dan berapa besar kasus yang terjadi di Indonesia. Selain itu, pada halaman ini juga menjelaskan secara singkat, dampak apa yang terjadi akibat stunting. Menu prediction akan menampilkan 2 halaman yang ditunjukkan pada Gambar 12 dan 13. 

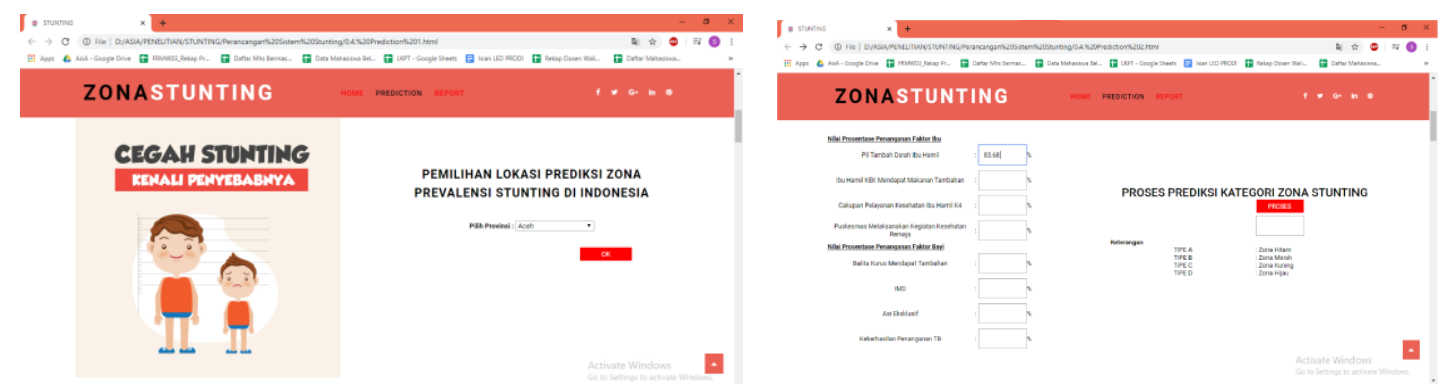

Gambar 13. a.Hasil Perancangan Menu Prediksi 1, b.Hasil Perancangan Menu Prediksi 2

Pada menu ini, admin memilih provinsi mana yang akan dilakukan prediksi. Setelah memilih provinsi, maka admin akan masuk halaman prediction 2. Pada halaman ini admin akan memasukkan nilai prosentasi setiap penanganan faktor Ibu dan Bayi dari provinsi yang teah dipilih sebelumnya. Kemudian hasilnya akan menunjukkan kategori zona stunting, yaitu Zona A, B, C, atau D. Hasil perancangan menu Report ditunjukkan pada Gambar 14

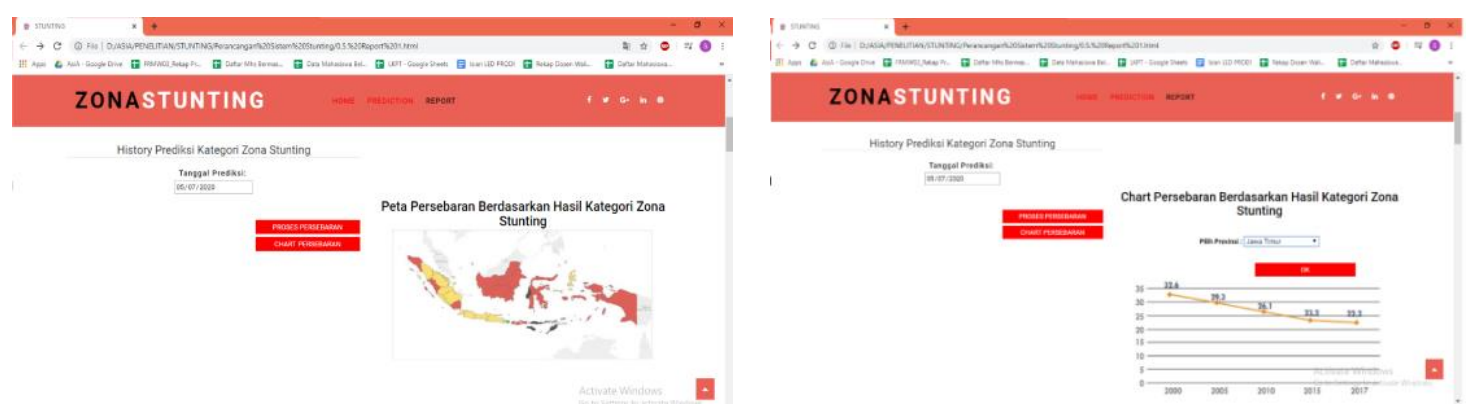

Gambar 14. Hasil Perancangan Menu Report (1), Hasil Perancangan Menu Report (2)

Pada Gambar 14 disediakan history prediksi yang dilakukan oleh admin. Disediakan fitur kalender untuk memudahkan admin memilih tanggal. Setelah klik proses persebaran akan muncul persebaran kategori zona stunting pada peta Indonesia. Warna disetiap provinsi mewakili tipe Zona. Berdasarkan Gambar 14, disediakan 2 button, yaitu untuk proses persebaran dan chart persebaran. Ketika admin klik chart persebaran, maka dapat memilih provinsi. Setelah itu akan muncul chart yang menampilkan bagaimana perubahan jumlah kasus stunting di provinsi tersebut setiap tahunnya, dan bagaimana hasil prediksi ditahun setelahnya.

\section{KESIMPULAN}

Perancangan sistem prediksi zona prevalensi stunting dengan menggunakan metode Agile perlu dilakukan beberapa kali proses identifikasi kebutuhan. Metode ini sangat tepat digunakan, karena perubahan kebutuhan dalam perancangan sistem ini dapat sering dilakukan dengan periode yang singkat. Dengan menggunakan metode Agile, sistem ini lebih sederhana dan dapat dikembangkan sesuai dengan kebutuhan. Hasil perancangan menunjukkan bahwa sistem akan dapat mengolah data untuk prediksi dan akan menampilkan data sebaran setiap provinsi.

\section{Daftar Pustaka}

[1] Kementrian Kesehatan RI, Buletin Jendela Data dan Informasi Kesehatan. Jakarta: Pusat Data dan Informasi, 2018.

[2] M. Syafi'ie, Tursina, and Yulianti, "Sistem Pendukung Keputusan Pemilihan Daerah Prioritas Penanganan Stunting pada Balita Menggunakan Metode TOPSIS (Studi Kasus : Kota Pontianak)," JUSTIN J. Sist. dan Teknol. Inf., vol. 7, no. 1, pp. 33-39, 2019.

[3] I. Sommerville, Software Engineering (Rekayasa Perangkat Lunak). Jakarta: Erlangga, 2011.

[4] I. Cahyono P. et al., "Perancangan Sistem Informasi Bagian Administrasi Mahasiswa dan Alumni (BAMA) Universitas Muhammadiyah Ponorogo Berbasis Web", Jurnal Ilmiah NERO, Vol. 5, no. 1. 
[5] Z. Arwaning Tyas, "Analisis Sistem Informasi Penjadwalan Universitas 'Aisyiyah Yogyakarta", Jurnal Ilmiah NERO, Vol. 4, no. 2.

[6] D. Mayasari et al., "Stunting, Faktor Resiko dan Pencegahannya Stunting, Risk Factor and Prevention", vol. 5, pp. 540-545, 2018.

[7] W. F. Wellina, M. I. Kartasurya, and M. Z. Rahfilludin, "Faktor Risiko Stunting pada Anak Umur 12-14 bulan", vol. 5, no. 1, pp. 55-61, 2016.

[8] N. N. Widyaningsih and S. Anantanyu, "Jurnal Gizi Indonesia Keragaman Pangan, Pola Asuh Makan dan Kejadian Stunting pada Balita Usia 24-59 Bulan", vol. 7, no. 1, 2018

[9] W. Kerja and P. Sirampog, "Unes Journal of Public Health". vol. 6, no. 3, 2017.

[10] Fatwanto, A. 2013. Metode Agile. (A. Pendanwangi, Interviewer). Yogyakarta. 